\title{
A randomized, prospective pilot comparison of 3 atrial appendage elimination techniques: Internal ligation, stapled excision, and surgical excision
}

\author{
Richard Lee, MD, MBA, ${ }^{a}$ Patricia Vassallo, MD, ${ }^{b}$ Jane Kruse, BS, RN, ${ }^{b}$ S. Chris Malaisrie, MD, \\ Vera Rigolin, MD, ${ }^{\mathrm{b}}$ Adin-Cristian Andrei, $\mathrm{PhD},{ }^{\mathrm{b}}$ and Patrick McCarthy, $\mathrm{MD}^{\mathrm{b}}$
}

\begin{abstract}
Background: Elimination of the left atrial appendage (LAA) attempts to reduce stroke in patients with atrial fibrillation $(\mathrm{AF})$. A retrospective review suggests that various surgical techniques are often unsuccessful and may leave a stump or gap. In a pilot study, we prospectively evaluated 3 surgical techniques with long-term follow up to define effectiveness.
\end{abstract}

Methods: At a single institution, 28 patients undergoing concomitant AF surgery were randomized prospectively into 1 of 3 techniques of LAA elimination: internal suture ligation (IL), external stapled excision (StEx), and surgical excision (SxEx). The success of LAA elimination was assessed by transesophageal echocardiography (TEE) in all patients at the time of surgery. Failure of LAA closure consisted of either a stump (residual appendage tissue $>1 \mathrm{~cm}$ in maximum length) or a gap (persistent flow between the left atrium [LA] and the LAA). Failure was treated intraoperatively when recognized. Late follow-up was obtained using a TEE at a mean of 0.4 years in $21 / 28(75 \%)$ of patients.

Results: Early failure was recognized and treated in 1 patient in the IL group $(13 \%), 6$ patients in the StEx group $(60 \%)$, and 2 patients in the SxEx group $(20 \%)(P=.06)$. On follow-up TEE, 4 of 7 patients in the IL group $(57 \%)$ had developed gaps, 3 of whom (43\%) with greater than mild flow. No patients in the StEx or SxEx groups had a gap $(P=.03)$. In late follow-up, 1 of 7 patients in the IL group (14\%) had a stump, compared with 2 of $8(25 \%)$ in the StEx group and 3 of $6(50 \%)$ in the SxEx group $(P=.35)$. The overall failure rate was $57 \%: 5$ of $8(63 \%)$ in the IL group, 6 of $10(60 \%)$ in the StEx group, and 5 of $10(50 \%)$ in the SxEx group $(P=.85)$. No patient had a stroke at any time during follow-up.

Conclusions: LAA elimination is often incomplete and goes undetected. If the LAA is eliminated at the time of surgery, then TEE should be used intraoperatively to assess effectiveness and reintervention performed if warranted. Late assessment for completeness of closure should be considered before cessation of anticoagulation until more effective LAA techniques can be developed. (J Thorac Cardiovasc Surg 2016;152:1075-80)

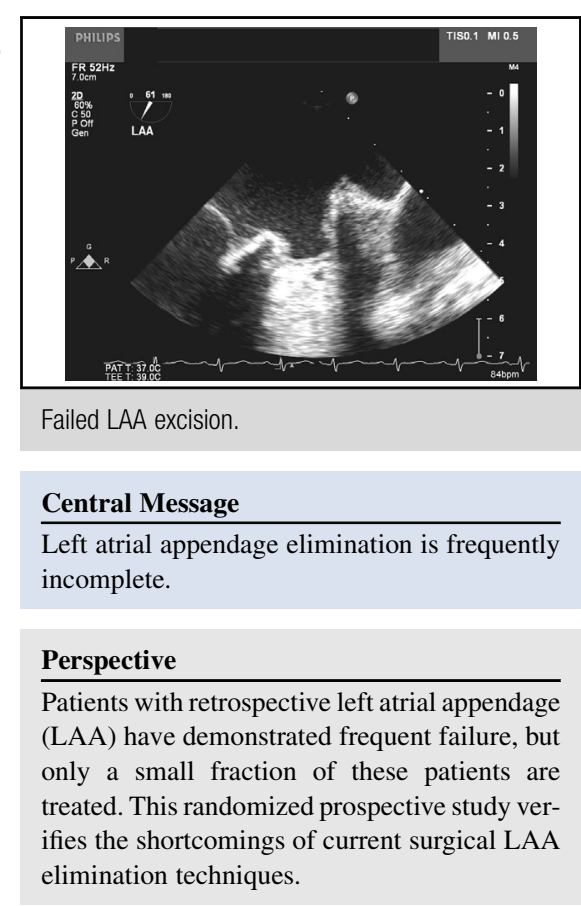

See Editorial Commentary page 1081.
Atrial fibrillation (AF) is the most common arrhythmia worldwide, and the incidence continues to increase in epidemic proportions. The left atrial appendage (LAA) is

\footnotetext{
From the ${ }^{\mathrm{a} C e n t e r}$ for Comprehensive Cardiovascular Care, Saint Louis University, St Louis, Mo; and ${ }^{\mathrm{b}}$ Bluhm Cardiovascular Institute, Northwestern University, Chicago, Ill

Received for publication Sept 18, 2015; revisions received March 25, 2016; accepted for publication June 9, 2016; available ahead of print July 12, 2016.

Address for reprints: Richard Lee, MD, MBA, Center for Comprehensive Cardiovascular Care, Saint Louis University, 3635 Vista Ave, DT 13th Floor, St Louis, MO 63110 (E-mail: rlee@slu.edu).

$0022-5223 / \$ 36.00$

Copyright (C) 2016 by The American Association for Thoracic Surgery http://dx.doi.org/10.1016/j.jtcvs.2016.06.009
}

emerging as an important target for stroke reduction in patients with AF. The LAA is the site of thrombus in $90 \%$ of nonrheumatic AF patients with stroke, ${ }^{1,2}$ and LAA obliteration is an integral part of the maze operation. ${ }^{3}$ In late follow-up, the combination of LAA elimination with an $\mathrm{AF}$ procedure has demonstrated a reduction

Scanning this QR code will take you to the article title page.

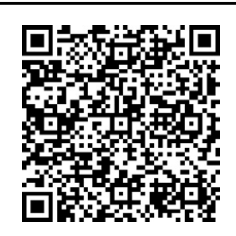




$$
\begin{aligned}
& \text { Abbreviations and Acronyms } \\
& \text { AF }=\text { atrial fibrillation } \\
& \text { IL }=\text { internal suture ligation } \\
& \text { LA }=\text { left atrium } \\
& \text { LAA }=\text { left atrial appendage } \\
& \text { StEx }=\text { external stapled excision } \\
& \text { SxEx }=\text { surgical excision } \\
& \text { TEE }=\text { transesophageal echocardiography }
\end{aligned}
$$

in expected stroke after surgical treatment of $\mathrm{AF}^{4,5}$ More recently, interest in the LAA has increased because percutaneous implantation of a device that excludes the LAA has proven to be as effective as warfarin, ${ }^{6}$ and is now approved by the US Food and Drug Administration.

Unfortunately, recent retrospective reviews of patients undergoing transesophageal echocardiography (TEE) for various indications have shown that surgery for LAA elimination often fails, with rates exceeding $50 \%$. $^{7-9}$ These studies have been limited by an unknown denominator, however, because the overwhelming majority of patients receiving intervention had no postoperative assessment. A prospective assessment of surgical LAA ligation is unavailable. We performed a pilot trial of 3 surgical techniques-internal ligation (IL), stapled excision (StEx), and surgical excision (SxEx) - to provide necessary and sufficient data for the design of a definitive trial.

\section{MATERIALS AND METHODS}

The study was approved by Northwestern University's Institutional Review Board (no. STU00031186) and funded by a private donor. The patients consented to the study, which included randomization into surgical technique and late follow-up TEE. At a single institution, 28 patients undergoing combined surgery for mitral repair or replacement and AF were randomized into 1 of the 3 surgical LAA elimination techniques by 1 of 4 surgeons. Patients age $>70$ years and those with renal failure or previous sternotomy were excluded. Eight patients underwent IL using a double-layer running Prolene suture (Ethicon, Somerville, NJ) to eliminate the orifice. Ten patients underwent StEx using an Endo GIA stapler (Covidien, Sunnyvale, Calif), and 10 patients underwent SxEx with edge reapproximation using a running Prolene suture. Subsequently, 1 patient in the SxEx group was deemed too fragile for excision and so underwent IL.

The success of closure was assessed in real time in multiple views after cessation of cardiopulmonary bypass by an experienced echocardiographer. Success was determined based on previously reported criteria, ${ }^{7}$ including no remnant pouch $>1 \mathrm{~cm}$ in maximum length after closure (stump) and the absence of a color flow jet between the left atrium (LA) and the LAA (gap). Persistent flow was further divided into none, trace, mild, and greater than mild. Images were saved and blindly assessed after deidentification. Surgeons were allowed to modify the appendage at the time of surgery with additional sutures or free tie ligation (IL); however, this was counted as an early failure in technique. The AF procedure was predominately a left or biatrial Cox maze IV with bipolar radiofrequency and cryothermia at the isthmus. Late TEEs were performed after 3 months, with the same criteria were used to determine success or failure. Overall failure was defined as presence of a gap or a stump on either TEE. In addition, length, base width, and widest width of the LAA were recorded.

Comparisons of continuous variables were performed using 1-way analysis of variance or the Kruskal-Wallis test. For categorical variables, proportions are presented, and group comparisons are based on the $\chi^{2}$ test or Fisher's exact test. Statistical significance was declared at the 2 -sided $5 \% \alpha$ level, and there were no multiplicity adjustments. Exact methods for binomial proportions were used to create $95 \%$ confidence intervals.

\section{RESULTS}

Baseline, intraoperative, and postoperative demographic data were comparable (Table 1). The patient designations and flow are provided in a CONSORT diagram in Figure 1.

\section{Safety}

There were no operative or 30-day deaths, no reexplorations for bleeding, and no early strokes or transient ischemic attacks. There were no significant differences among the groups in length of hospital stay (7 days) or readmission $(10 \%)$. During follow-up, there were 2 late deaths, both in the StEx group $(P=.14)$. There were no late strokes.

\section{Efficacy}

Early results are presented in Table 2 . There was a trend toward a greater need for intraoperative intervention in the StEx group $(P=.06)$, in which 3 patients had a large stump and 3 patients had bleeding, compared with 1 large stump and 1 case of bleeding in the SxEx group and none of either in the IL group. Although there was no statistical difference among the 3 groups, none of the IL patients had a stump, and only 1 patient with excision of any kind had residual flow.

Late follow-up TEE was performed in $75 \%$ of all patients, at a mean of $0.4 \pm 0.1$ years (Table 3). The IL group had a higher rate of gaps and significantly greater flow $(P=.03)$. More than one-half of all interventions failed. On late follow-up, there were no strokes and no reoperations for any valve.

Overall failure of LAA elimination (early plus late) was $57 \%$, including 5 of $8(63 \%)$ in the IL group, 6 of $10(60 \%)$ in the StEx group, and 5 of $10(50 \%)$ in the SxEx group $(P=.85)$.

\section{DISCUSSION}

Although this was only a feasibility study, our data suggest that complete elimination of the LAA should not be assumed with any of the current surgical techniques. This finding is consistent with the results of previous retrospective studies. ${ }^{2,7,8}$ Initially, internal ligation usually provides a stump-free elimination, but often tears through the tissue, likely because of tension, causing a 
TABLE 1. Baseline demographics, intraoperative metrics, and postoperative outcomes

\begin{tabular}{|c|c|c|c|}
\hline Variable & $\begin{array}{l}\text { Internal ligation } \\
\quad(n=8)\end{array}$ & $\begin{array}{l}\text { Stapled excision } \\
\quad(\mathbf{n}=10)\end{array}$ & $\begin{array}{l}\text { Surgical excision } \\
\quad(\mathbf{n}=10)\end{array}$ \\
\hline Age, $y$, mean \pm SD & $69 \pm 7.0$ & $67.9 \pm 8.9$ & $66.9 \pm 7.3$ \\
\hline Body mass index, mean $\pm \mathrm{SD}$ & $26.7 \pm 4.9$ & $28.5 \pm 5.5$ & $27.9 \pm 5.5$ \\
\hline $\mathrm{CHADS}_{2}$ score, mean $\pm \mathrm{SD}$ & $1.4 \pm 0.9$ & $2.1 \pm 1.1$ & $1.5 \pm 1.2$ \\
\hline Creatinine, mg/dL, median (IQR) & $1.0(0.8-1.1)$ & $1.1(0.9-1.6)$ & $1.2(1.0-1.5)$ \\
\hline Ejection fraction, $\%$, median (IQR) & $56.5(52.5-62.5)$ & $58(50-62)$ & $61.5(55-72)$ \\
\hline Left atrial size, $\mathrm{cm}$, median (IQR) & $4.2(3.6-4.6)$ & $4.6(4.1-4.9)$ & $5.1(4.2-5.2)$ \\
\hline Duration of atrial fibrillation, $y$, median (IQR) & $2.0(1-12)$ & $4.0(2-7)$ & $2.0(1-7)$ \\
\hline Female sex, $\mathrm{n}(\%)$ & $2(25)$ & $5(50)$ & $6(60)$ \\
\hline Diabetes, n (\%) & $1(13)$ & $1(10)$ & $2(20)$ \\
\hline Hypertension, n (\%) & $6(75)$ & $8(80)$ & $7(70)$ \\
\hline Chronic lung disease, $\mathrm{n}(\%)$ & $0(0)$ & $1(10)$ & $2(20)$ \\
\hline Cerebrovascular disease, $\mathrm{n}(\%)$ & $0(0)$ & $0(0)$ & $1(10)$ \\
\hline Previous stroke, $\mathrm{n}(\%)$ & $0(0)$ & $1(10)$ & $0(0)$ \\
\hline Ambler score, mean $\pm \mathrm{SD}$ & $5.6 \pm 3.7$ & $11.1 \pm 14.5$ & $7.5 \pm 8.7$ \\
\hline \multicolumn{4}{|l|}{ NYHA class, $\mathrm{n}(\%)$} \\
\hline Class 1 & $5(71)$ & $1(10)$ & $2(20)$ \\
\hline Class 2 & $0(0)$ & $8(80)$ & $6(60)$ \\
\hline Class 3 & $2(39)$ & $1(10)$ & $2(20)$ \\
\hline Coronary artery disease, $\mathrm{n}(\%)$ & $3(38)$ & $4(40)$ & $2(20)$ \\
\hline Previous catheter ablation, $\mathrm{n}(\%)$ & $0(0)$ & $2(20)$ & $2(20)$ \\
\hline \multicolumn{4}{|l|}{ Atrial fibrillation type, $\mathrm{n}(\%)$} \\
\hline Paroxysmal & $4(57)$ & $6(60)$ & $6(60)$ \\
\hline Long-standing persistent & $2(29)$ & $3(30)$ & $2(20)$ \\
\hline Persistent & $1(14)$ & $1(10)$ & $2(20)$ \\
\hline Perfusion time, min, median (IQR) & $109(96-119)$ & $122.5(87-140)$ & $93(88-121)$ \\
\hline Cross-clamp time, min, median (IQR) & $73.5(65.5-98.5)$ & $87.5(74-99)$ & $81(75-84)$ \\
\hline Concomitant CABG, n (\%) & $1(13)$ & $3(30)$ & $2(20)$ \\
\hline Tricuspid surgery, n (\%) & $4(50)$ & $3(30)$ & $2(20)$ \\
\hline Postoperative length of stay, d, median (IQR) & $7(5-7.5)$ & $6.5(6-14)$ & $8(7-12)$ \\
\hline Readmitted to ICU, n (\%) & $0(0)$ & $1(10)$ & $1(10)$ \\
\hline Reoperation for bleeding, $\mathrm{n}(\%)$ & $0(0)$ & $0(0)$ & $0(0)$ \\
\hline Postoperative stroke, n (\%) & $0(0)$ & $0(0)$ & $0(0)$ \\
\hline Postoperative TIA, n (\%) & $0(0)$ & $0(0)$ & $0(0)$ \\
\hline Mortality, n (\%) & $0(0)$ & $0(0)$ & $0(0)$ \\
\hline
\end{tabular}

$S D$, Standard deviation; $I Q R$, interquartile range; $N Y H A$, New York Heart Association; $C A B G$, coronary artery bypass grafting; $I C U$, intensive care unit; $T I A$, transient ischemic attack.

gap (Figure 2), which causes residual flow later in follow-up. In addition, if patients maintain sinus rhythm, contraction of the LAA may add additional force, causing sutures to pull through the tissue. The failure of this technique is not likely to be identified unless TEE is performed in late follow-up. A stump is more common in excision, both surgical and stapled, and is often present at the time of the operation (Figure 3). Examining the LAA before closure of the chest with intraoperative TEE allows for intervention to address these failures at the time of the initial procedure.

These data highlight a critical need for closer postprocedure examination after LAA elimination. In addition, based on previous reports, further refinement of surgical techniques likely will be needed to improve the results, and should be developed before a definitive study is undertaken. Moreover, the data suggest that late TEE follow-up is helpful in patients with persistent flow, given that the gap widened in some patients, and might affect a clinician's decision regarding cessation of anticoagulation. Routine late evaluation may benefit a number of patients and should be considered.

An important concern is that incomplete ligation may increase stroke. ${ }^{9}$ Based on findings from this pilot trial and the observations of others, this concept may or may not be correct. There are limited data to support either perspective, but the topic merits some discussion, because these results could be interpreted in favor of a "do nothing" approach. Several studies indirectly support the efficacy of LAA closure in stroke reduction, even when the techniques may leave an incomplete elimination. The Watchman device occludes the LAA, but leaks occur around the device 


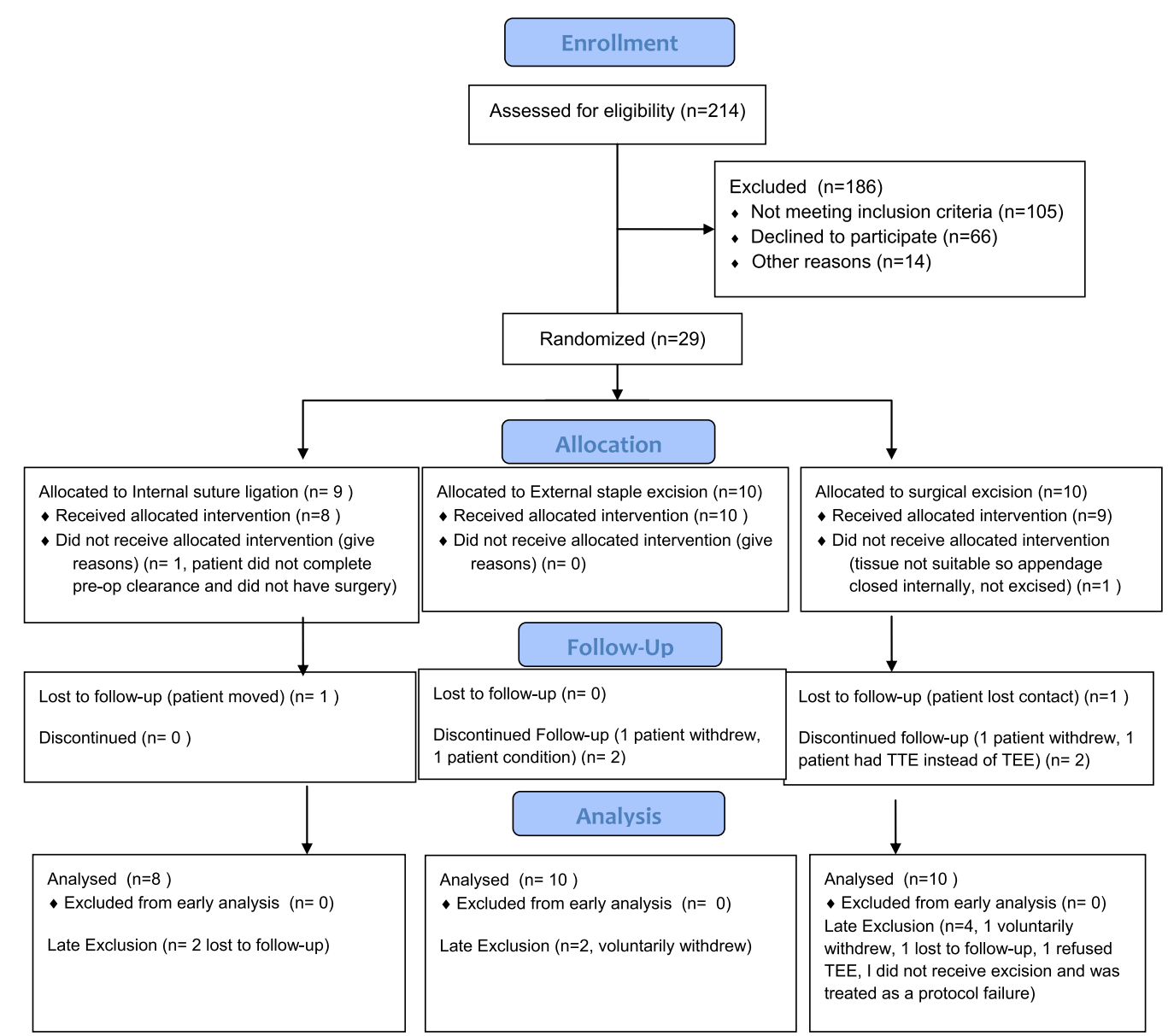

FIGURE 1. CONSORT diagram of the study. TTE, Transthoracic echocardiogram; TEE, transesophageal echocardiography.

approximately $30 \%$ of the time. Despite imperfect closure, the Watchman device proved as effective as anticoagulation in stroke reduction in a large, randomized prospective study; however, these leaks were often relatively small, with a mean size of $3 \mathrm{~mm}$. Nonetheless, this did not affect late stroke, even off anticoagulation. In our previous work, we analyzed several alternative closure techniques, including the 3 used here, and their implications for late stroke. ${ }^{5}$ We found that although late strokes and transient ischemic attacks do occur after intervention, they are infrequent, with a rate of roughly $1 \%$, an event rate comparable to a $\mathrm{CHADS}_{2}$ score of 1 on therapeutic anticoagulation. ${ }^{10}$

Although the clinical evidence is limited, we hypothesize that even when incomplete, elimination techniques may reduce the clot burden. This may influence the severity of the event. For example, in AF patients in whom the LAA is untreated, $\mathrm{AF}$ strokes are at least twice as likely to be fatal

TABLE 2. Intraoperative evaluation of LAA elimination

\begin{tabular}{lccc}
\hline \multicolumn{1}{c}{ Variable } & Internal ligation $(\mathbf{n}=\mathbf{8})$ & Stapled excision $(\mathbf{n}=\mathbf{1 0})$ & Surgical excision $(\mathbf{n}=\mathbf{1 0})$ \\
\hline LAA failure, $\mathrm{n}(\%)[95 \% \mathrm{CI}]$ & $2(25)[0.032-0.651]$ & $6(60)[0.262-0.878]$ & $4(40)[0.121-0.738]$ \\
Extra sutures used, $\mathrm{n}(\%)[95 \% \mathrm{CI}]$ & $1(13)[0.003-0.527]$ & $6(60)[0.262-0.878]$ & $2(20)[0.025-0.556]$ \\
Residual stump >1 cm present, $\mathrm{n}(\%)[95 \% \mathrm{CI}]$ & $0(0)[0-0.369]$ & $1(10)[0.003-0.445]$ & $2(20)[0.025-0.556]$ \\
Gap present, n $(\%)[95 \% \mathrm{CI}]$ & $1(13)[0.003-0.527]$ & $0(0)[0-0.308]$ & $1(10)[0.003-0.445]$ \\
Flow, n $(\%)[95 \% \mathrm{CI}]$ & & & \\
Greater than mild & $1(13)[0.003-0.527]$ & $0(0)[0-0.308]$ & $0(0)[0-0.308]$ \\
Mild & $0(0)[0-0.369]$ & $0(0)[0-0.308]$ & $1(10)[0.003-0.445]$ \\
Trace & $1(13)[0.003-0.527]$ & $0(0)[0-0.308]$ & $0(0)[0-0.308]$ \\
None & $6(75)[0.349-0.968]$ & $10(100)[0.692-1]$ & $9(90)[0.555-0.997]$ \\
\hline
\end{tabular}

LAA, Left atrial appendage; $C I$, confidence interval. 
TABLE 3. Late evaluation of LAA elimination

\begin{tabular}{|c|c|c|c|}
\hline Variable & Internal ligation $(n=7)$ & Stapled excision $(n=8)$ & Surgical excision $(n=6)$ \\
\hline Residual stump $>1 \mathrm{~cm}$ present, $\mathrm{n}(\%)[95 \% \mathrm{CI}]$ & $1(14)[0.004-0.579]$ & $2(25)[0.032-0.651]$ & $3(50)[0.118-0.881]$ \\
\hline Gap present, $\mathrm{n}(\%)[95 \% \mathrm{CI}]$ & $3(43)[0.099-0.816]$ & $0(0)[0-0.369]$ & $0(0)[0-0.45]$ \\
\hline \multicolumn{4}{|l|}{ Flow, n $(\%)[95 \% \mathrm{CI}]$} \\
\hline Greater than mild flow & $3(43)[0.099-0.816]$ & $0(0)[0-0.369]$ & $0(0)[0-0.459]$ \\
\hline No flow & $4(57)[0.184-0.901]$ & $8(100)[0.631-1]$ & $6(100)[0.540-1]$ \\
\hline
\end{tabular}

CI, Confidence interval

as patients with stroke from other causes, with a 30-day mortality of $\geq 25 \% .^{11}$ In contrast, in our Northwestern series, after treatment, only 1 late stroke $(6 \%)$ was fatal. ${ }^{5}$ These data may suggest that a decreased clot burden decreases the severity of ischemic events. This is further suggested by the Kanderian et al study, in which even though 28 patients with unsuccessful ligations had some thrombus in the LAA, there was no difference in stroke rate between unsuccessful and successful closures. ${ }^{7}$ Furthermore, other authors have demonstrated that late stoke rate is not effected by $\mathrm{CHADS}_{2}$ score after intervention. $^{12,13}$ A limited understanding of stroke rate after incomplete elimination also may be influenced by the fact that TEE is currently performed routinely only in patients after elimination of LAA for a clinical indication, including stroke. More data are needed before conclusions can be drawn in either direction, and we await a sufficiently powered trial with long-term follow-up to do so.

Some discrepancies with other studies need to be addressed. The success rate in the study of Kanderian et al was higher for surgical excision ${ }^{7}$ compared with the present study $(73 \%$ vs $50 \%)$. This may be related to surgical technique, but 3 of the surgeons in the present study were at the Cleveland Clinic during the time of that data collection, so it is likely that the techniques were similar. The study by Kanderian et al was retrospective and included

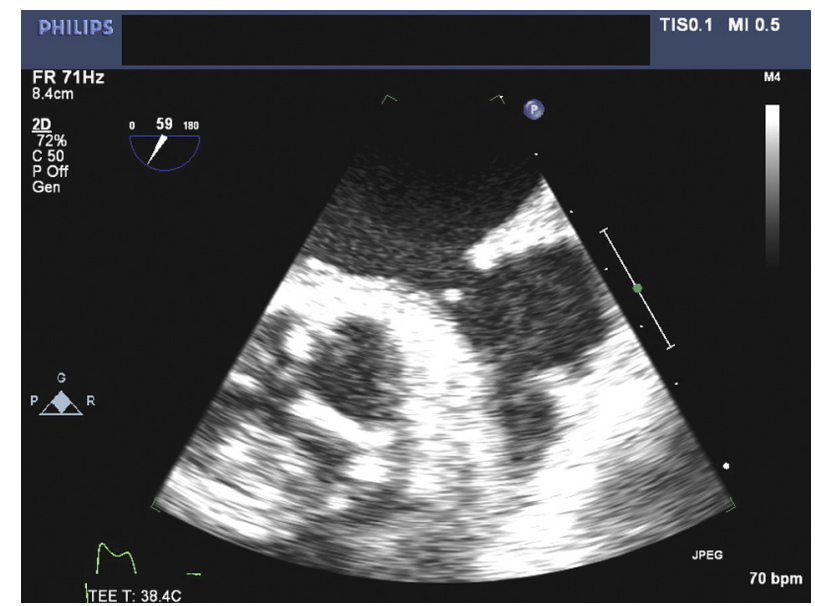

FIGURE 2. Failure of internal ligation because of a residual gap. TEE, Transesophageal echocardiography. only 137 of 2546 patients (5\%) who underwent TEE after surgical closure, which limits comparison. A larger prospective sample is needed before success rates can be cited with confidence. Before this study, no data existed to adequately calculate the sample size needed to demonstrate a difference in techniques. Using this data, assuming a success rate of $40 \%$ to $60 \%$, the estimated sample size ranges from 270 (using success rates of $60 \%, 60 \%$, and $40 \%$ ) to 1080 (using success rates of $60 \%, 50 \%$, and $50 \%$ ). This would likely require a multi-institutional design.

Although we have cited several studies reporting an extremely low incidence of stoke after AF surgery, other reports have disagreed. Buber et $\mathrm{al}^{14}$ reported up to a $10 \%$ late stroke rate after AF surgery in patients with electrical sinus rhythm. Large atria and poor contractility were cited as risk factors. Unfortunately, the percentage of rheumatic patients was not recorded in this series, nor was the type of LAA elimination and the success rate. In light of the other reports, this stroke rate is likely higher than expected, but does highlight the need to consider late evaluation. It has been demonstrated that even in "successful" LAA closure with a stump of $<1 \mathrm{~cm}$ on anticoagulation, thrombus may be present. ${ }^{15}$ Subsequently, some now recommend evaluating all patients by TEE before the decision to eliminate anticoagulation.

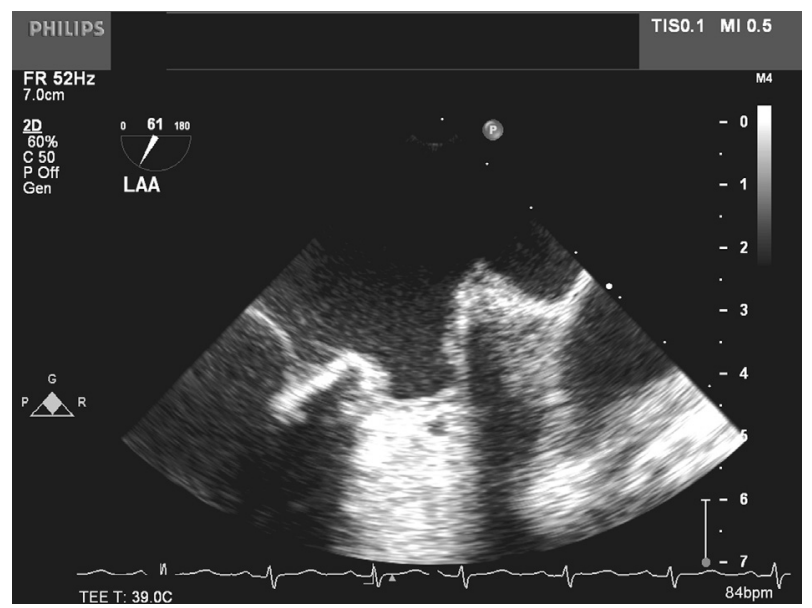

FIGURE 3. Failure of stapled excision because of a residual stump. $L A A$, Left atrial appendage; TEE, transesophageal echocardiography. 
This study has several limitations. This was only a feasibility study with a small sample size, and a larger sample may yield differences between groups or different results altogether. A larger, more definitive study is needed, but will require significantly more funding and multi-institutional collaboration. Despite our best efforts, late follow-up was not complete. This might have influenced the percentages of complete elimination in either direction. Complete follow-up could have demonstrated somewhat better or worse rates of success. Furthermore, differences in surgical technique could be questioned; however, each surgeon in this study was not only an experienced surgeon, but also an experienced AF surgeon with numerous publications in the field. Moreover, the single conversion to an internal ligation for frail tissue in the surgical excision group might have confounded the results. The decision to include additional ligation for bleeding as a failure may be debated as well. Nonetheless, each of these interventions reduced the size of the stump; moreover, most of us consider bleeding to be a failure independently, because it could be fatal.

Future studies should examine the relative impact, if any, of a stump compared with a gap. Most critically, we need to develop techniques that do not leave stumps, gaps, or bleeding. This study is the first to prospectively evaluate different surgical techniques, clarifying the denominator and comparing the failure rate between types. Substantial future investigation in a larger sample is needed to define true rates of failure.

\section{CONCLUSIONS}

Contemporary LAA techniques remain inadequate owing to incomplete closure of the LAA, and improved methods are needed. Additional studies are warranted to investigate the impact of incomplete closure on clinical outcomes. Results should improve through examination of the LAA in real time in the operating room with intraoperative TEE and performing any necessary interventions before chest closure. As our understanding continues to evolve, we recommend using TEE to evaluate the efficacy of LAA closure before cessation of anticoagulation.

\section{Conflict of Interest Statement}

Authors have nothing to disclose with regard to commercial support.

\section{References}

1. Blackshear JL, Odell JA. Appendage obliteration to reduce stroke in cardiac surgical patients with atrial fibrillation. Ann Thorac Surg. 1966;61:755-9.

2. Manning WJ, Silverman DI, Katz SE, Riley MF, Come PC, Doherty RM, et al. Impaired left atrial mechanical function after cardioversion: relation to the duration of atrial fibrillation. J AM Coll Cardiol. 1994;23:1535-40.

3. Cox JL. The surgical treatment of atrial fibrillation, IV: surgical technique. J Thorac Cardiovasc Surg. 1991;101:584-92.

4. Cox JL, Ad N, Palazzo T. Impact of the maze procedure on the stroke rate in patients with atrial fibrillation. J Thorac Cardiovasc Surg. 1999;118:833-40.

5. Lee R, Jivan A, Kruse J, McGee EC Jr, Malaisrie SC, Bernstein R, et al. Late neurologic events after surgery for atrial fibrillation: rare but relevant. Ann Thorac Surg. 2013;95:126-32.

6. Reddy VY, Sievert H, Halperin J, Doshi SK, Buchbinder M, Neuzil P, et al. Percutaneous left atrial appendage closure vs warfarin for atrial fibrillation: a randomized clinical trial. JAMA. 2014;312:1988-98.

7. Kanderian AS, Gillinov AM, Pettersson GB, Blackstone E, Klein AL. Success of surgical left atrial appendage closure: assessment by transesophageal echocardiography. J Am Coll Cardiol. 2008;52:924-9.

8. Katz ES, Tsiamtsiouris T, Applebaum RM, Schwartzbard A, Tunick PA, Kronzon I. Surgical left atrial appendage ligation is frequently incomplete: a transesophageal echocardiographic study. J Am Coll Cardiol. 2000;36: 468-71.

9. García-Fernández MA, Pérez-David E, Quiles J, Peralta J, García-Rojas I, Bermejo J, et al. Role of left atrial appendage obliteration in stroke reduction in patients with mitral valve prosthesis: a transesophageal echocardiographic study. J Am Coll Cardiol. 2003;42:1253-8.

10. Lip GY, Nieuwlaat R, Pisters R, Lane DA, Crijns HJ. Refining clinical risk stratification for predicting stroke and thromboembolism in atrial fibrillation using a novel risk factor-based approach: the Euro Heart Survey on Atrial Fibrillation. Chest. 2010;137:263-72.

11. Lin HJ, Wolf PA, Kelly-Hayes M, Beiser AS, Kase CS, Benjamin EJ, et al. Stroke severity in atrial fibrillation: the Framingham Study. Stroke. 1996;27:1760-4.

12. Ad N, Henry L, Shuman DJ, Holmes SD. A more specific anticoagulation regimen is required for patients after the Cox maze procedure. Ann Thorac Surg. 2014;98:1331-8.

13. Pet M, Robertson JO, Bailey M, Guthrie TJ, Moon MR, Lawton JS, et al. The impact of $\mathrm{CHADS}_{2}$ score on late stroke after the Cox maze procedure. J Thorac Cardiovasc Surg. 2013;146:85-9.

14. Buber J, Luria D, Sternik L, Raanani E, Feinberg MS, Goldenberg I, et al. Left atrial contractile function following a successful modified maze procedure at surgery and the risk for subsequent thromboembolic stroke. J Am Coll Cardiol. 2011;58:1614-21.

15. Hui DS, Alderson LJ, Lee R. Left atrial appendage thrombus after successful surgical exclusion on anticoagulation: a need for closer postintervention monitoring. Ann Thorac Surg. 2014;98:1478.

Key Words: left atrial appendage, atrial fibrillation, maze 